\title{
POTENTIAL APPLICATIONS OF NANOTECHNOLOGY IN PAVEMENT ENGINEERING
}

WJvdM Steyn PrEng, MSAICE ${ }^{1}$

\begin{abstract}
Nanotechnology is the term used to cover the design, construction and utilization of structures with at least one dimension measured in nanometers. Compared with typical civil engineering structures the two fields operate on hugely divergent dimensional scales. Nanotechnology initially developed in the fields of physics and chemistry, and most fundamental developments still occur in these fields. However, for the technology to affect society at large, it needs to be applied in areas such as the engineering field. This paper focuses specifically on current and potential developments in pavement engineering where the unique properties of nanomaterials may be utilized to deliver a better environment to society, based on identified needs and challenges in the pavement engineering field. It is demonstrated that there are essentially two areas where nanotechnology can complement pavement engineering. These are in the development of improved materials and the use of characterization methods to improve the understanding of materials. Examples of current and planned research in these areas are cited and discussed. Finally, current challenges in exploiting the unique properties of nanomaterials in pavement engineering are indicated and discussed. The paper demonstrates that although the majority of the fundamental developments in nanoscale science and technology are occurring in the fundamental physics, chemistry and typically electronic engineering fields, the potential for this technology to impact on the quality of life of society at large is huge.
\end{abstract}

\footnotetext{
${ }^{1}$ Assistant Professor, Department of Civil Engineering, University of Pretoria, Pretoria, South Africa Lynnwood Road, Hatfield, 0002, South Africa

Phone: +27 124202171

Email:wynand.steyn@up.ac.za

PrEng - Professional Engineer - Engineering Council of South Africa

MSAICE - Member of the South African Institute for Civil Engineering
} 


\section{SUBJECT HEADINGS}

Pavements, Material engineering, Imaging techniques, Innovation

\section{INTRODUCTION}

\section{Nanotechnology definitions}

Nanotechnology is the term used to cover the design, construction and utilization of functional structures with at least one characteristic dimension measured in nanometers (Kelsall et al, 2004). The field of nanotechnology has developed in major leaps during the past 10 years. These developments were mainly driven by factors such as dedicated initiatives into the field (e.g. the National Nanotechnology Initiative) (Goddard et al, 2007), improvements in the characterization equipment and a new understanding into the chemistry and physics of matter on the nano scale.

Although the major nanotechnology developments were initially (and still remain) in the fields of electronics, physics and chemistry, more recent applications emerged in fields such as engineering. This can mainly be attributed to the improved understanding of the physics and chemistry of materials at nano-level, and the consequent development of specific applications for typical engineering level challenges. Although much is being written regarding the potential application of nanotechnology in these fields, a lot of this may be deemed speculation and still requiring a quantum leap to bridge the (mainly) dimensional divide between nano and macro structures.

\section{Science and engineering definitions}

Chemistry is the science concerned with the composition, structure, and properties of matter, as well as the changes it undergoes during chemical reactions. Physics is the science that deals with concepts such as force, energy, and mass with the goal of understanding the natural world. Engineering is the creative application of scientific principles to design, develop, manufacture and operate structures, machines, manufacturing processes or works while acknowledging issues around economics of 
operation and safety to life and property. Pavement engineering is an engineering discipline that deals with the design and construction of infrastructure such as roads and bridges.

Based on these four definitions, it is clear that the objectives of science (chemistry and physics) and engineering differ in that the sciences are more concerned with the composition, structure and interrelationships of matter, while engineering is more concerned with applying these principles in support of humanity. As such, engineering is thus dependent to a large degree on the principles developed in the sciences, but focus on the application of these in support of humanity. It is important to realize that while chemistry and physics generally focus on the smaller scales to enable a more detailed understanding of matter, engineering typically focuses on the scale where the matter works together to perform certain function (e.g. cement particles that combine with aggregate particles to form a concrete road pavement or building). The scale dimensions thus differ from the nanoscale understanding for the sciences to the macroscale understanding for engineering.

\section{Paper focus - nanotechnology to infrastructure}

The focus of this paper is to evaluate how knowledge and understanding of matter on a nanotechnology scale (based on chemistry and physics principles) can serve humankind through application of these knowledge and principles in engineering structures. It is thus important that scientific knowledge needs to be converted into technologies that can benefit society. In this paper, the focus is specifically on current and potential developments in pavement engineering where the unique properties of nanomaterials are utilized to improve the built environment.

The paper has started with definitions for engineering and the sciences to illustrate how the objectives of the two disciplines differ, and how they can support each other. Current needs in the pavement engineering field are summarized as a basis for discussing the research context and potential applications and benefits of nanotechnology to pavement engineering. The paper then demonstrates that nanotechnology should not be implemented in the pavement engineering arena merely because it is a new technology, but to address these specific challenges that can not readily be solved using 
existing macro-scale technologies. Two areas where nanotechnology and pavement engineering can complement each other are identified and specific examples of current and potential nanotechnologybased applications discussed. Finally, challenges in exploiting the unique properties of nanomaterials in pavement engineering are highlighted and discussed. Overall, the paper demonstrates that although the majority of the fundamental developments in nanoscale science and technology are occurring in the fundamental physics and chemistry fields, the potential for this technology to impact on the quality of life of society at large is huge.

\section{PAVEMENT ENGINEERING CONTEXT}

\section{Scale factors}

The scale chasm between typical nanotechnology and pavement engineering has been illustrated by various researchers (Buehler and Ackbarow, 2007; Larsen-Basse and Chong, 2005). It can also be illustrated when the potential application of carbon nanotubes (CNTs) as fibers in fiber reinforced concrete is evaluated. Typically, the volume of steel or polypropylene fibers used for such an application may be in the region of 2 per cent. If it is assumed that the application rate of the CNTs in the concrete will be similar to that of the steel fibers, this translates to approximately $270 \mathrm{~kg}$ of steel fibers (for a typical steel fiber reinforced pavement of $1 \mathrm{~km}$ - $7.4 \mathrm{~m}$ wide and $100 \mathrm{~mm}$ thick concrete) being replaced by $52 \mathrm{~kg}$ of CNTs. A typical pavement rehabilitation project (10 km to $100 \mathrm{~km}$ length) may thus require in the order of $520 \mathrm{~kg}$ to $5200 \mathrm{~kg}$ of CNTs. The economical production of such volumes of CNTs may not be realistic at this stage. The dimensional jump from nanoscale to macroscale thus influences the potential usage of nano-materials.

\section{Current needs}

Meyyapan et al (2007) presented a summary of the expectations from emerging alternative technologies for CNT electronic devices. It was indicated that a clear understanding of the expectations of a novel technology is required in order to evaluate the technology and ensure that the technology can deliver optimally. Only once the current needs are well defined, can applications be 
explored. In this regard the need to develop the expectation list of nanotechnology for pavement engineering is required. It is also important to realize that pavement engineering projects that specifically focus on the delivery of sustainable road pavements to the traveling public are typically funded through public money, and therefore the responsibility of how this funding is applied in road pavement projects has to be such that the public can trust that this funding is not wasted. Ultimately, tax dollars are used to supply and maintain a safe and reliable pavement network.

In order to summarize the current major needs of pavement engineering, proceedings from recent conferences in the pavement and transport arena were scanned. Based on the proceedings of the recent International Conference on Asphalt Pavements (ICAP - www.icap.com), PIARC meeting (www.PIARC.com), Transportation Research Board annual meeting (TRB - www.trb.org), Conference on Asphalt Pavements in Southern Africa (CAPSA - www.capsa.co.za) and South African Transportation Conference (Steyn, 2008a), the major current needs for pavement engineering can be summarized in terms of the technical committee structure adopted by PIARC (Table 1). For the purpose of this paper, the Technical Committees on Road pavements, Road bridges and related structures and Earthworks, drainage and subgrade are the most relevant. Selected identified issues and strategies for these are also summarized in Table 1.

The major current needs in pavement engineering where nanotechnology can potentially play a role is most probably the improved use of existing and available materials and the processing of these materials to enable them to fulfill the required specifications of perpetual pavement structures. In terms of the need for sustainable pavements (which is probably the primary current need), Maher et al (2006) defined the main criteria for a sustainable pavement as follows:

- Minimizing the use of natural resources;

- Reducing energy consumption;

- Reducing greenhouse gas emissions; 
- Limiting pollution (air, water, earth, noise);

- Improving health, safety, and risk prevention, and

- Ensuring a high level of user comfort and safety.

\section{RESEARCH CONTEXT}

In line with the earlier discussion on the focus difference between science and engineering, it is interesting to compare this with the types of research defined by the OECD (2002). These include four types of research, defined as follows:

- Basic research - experimental/theoretical work undertaken to acquire new knowledge of underlying foundations of phenomena, without particular application in view;

- Oriented basic research - carried out with the expectation that it will produce a broad base of knowledge likely to form the basis of the solution to recognized or expected problems;

- Applied research - original investigation undertaken in order to acquire new knowledge and directed primarily towards a specific practical aim or objective, and

- Experimental development - systematic work drawing on knowledge gained from research and practical experience that is directed to producing new materials, products and devices.

Using these definitions it is apparent that the majority of current chemistry- and physics-based research is focused on the first two levels, while the focus of engineering research is on the last two levels. However, this does not mean that the two broad areas are independent of each other. As an example of the route that research into nanotechnology should take, the following can be shown (typical references cited):

- $\quad$ Basic research - discovery of the buckyball and CNT (OECD, 2002);

- Oriented basic research - research into the basic properties of CNTs (Goddard et al, 2007) and the potential impact on the environment (Tong et al, 2007); 
- Applied research - evaluation of the manufacturing processes and compatibility and effects of CNTs with cement and aggregate (Makar et al, 2005; Yakovlev et al, 2006);

- Experimental development - application of CNTs as fibers in fiber reinforced concrete and as sensors in roads (Shi and Chung, 1999).

Clearly all four steps are required to ensure success in this research, and none of the steps can be ignored in a novel field such as nanotechnology to enable applications in traditional fields such as pavement engineering. The basic building blocks are required to ensure that the ultimate pavement does not fail prematurely through inadequate understanding and knowledge of the CNT.

Figure 1 (adapted from Sunter, 1996) provides an indication of the typical road to innovation. This figure is similar to many others indicating that new innovations take time and effort to get to fruition. What is significant is that optimism regarding potential breakthroughs is very strong during the first part of the innovation, and that this is often dampened by reality. Once the detailed work has been completed, the real potential of an innovation only starts to be realized. Currently, for many nanotechnology innovations the initial period of optimism and excitement still prevails and many major breakthroughs are anticipated based on initial basic and oriented basic research results. However, once realities regarding issues such as scale, dimensions and costs start to surface, the potential for these innovations to provide real value often starts to disappear. The important point to take from this reality is that for any innovation to provide real benefit in the pavement engineering field, there has to be a real positive benefit/cost ratio.

Based on the introductory discussions, the problem statement for potential applications of nanotechnology in pavement engineering can be summarized in terms of the following three points:

- Identify the current needs that can not be addressed effectively using current technology; 
- Identify the potential nanotechnology solutions that may be applicable in the pavement engineering field, and

- Marry the two concepts to identify nanotechnology solutions with the highest potential benefit/cost ratios and focus on specific developments in those fields.

In order to focus on this problem statement, the remainder of the paper investigates two areas where it is anticipated that nanotechnology can support pavement engineering with the highest potential for success.

\section{ENGINEERING APPLICATIONS}

Evaluation of the potential applications of nanotechnology in pavement engineering and the potential for pavement engineering to benefit from nanotechnology developments led the author to identify the following two main areas where nanotechnology can potentially support pavement engineering with the highest potential benefit/cost ratio (theses two areas are evaluated in terms of novel existing solutions to the problem using nanotechnology and novel potential solutions to the problem):

- Development of improved materials and

- Characterization of existing and novel materials.

\section{Development of improved materials}

The development of improved materials using nanotechnology techniques is one of the areas where probably the most can be achieved to enable beneficial impacts from nanotechnology in pavement engineering. Pavement engineers use a wide range of materials for the construction and maintenance of road pavements. Most of these materials are natural materials that are modified using products such as bitumen, cement and other chemical admixtures. The bulk of the material, however, remains naturally occurring aggregates and soils. Problems often exist in the application of these materials for specific conditions, i.e. incompatibility between certain aggregates and binders (bituminous or 
cementitious), deterioration of the material during certain environmental conditions (i.e. water susceptibility of granular materials and temperature sensitivity of bituminous materials) and deterioration with use (i.e. fatigue due to overloading). Current examples from the literature where nanotechnology techniques have been applied to enhance pavement engineering materials are as follows:

- Fracture behavior

○ Buehler and Ackbarow (2007) provided a discussion on the understanding of fracture mechanics to improve the ability to perform structural engineering on macro scale and introduced the concept of how dimensional scales interact with each other.

- Kumar and Curtin (2007) evaluated crack and microstructure interaction with a discussion on the understanding of initiation of cracks in metals.

- The concepts discussed in these two references can similarly be adapted to improve the nanoscale understanding of crack development in the bituminous binder / aggregate interface as well as cracking of concrete on pavements.

- Self healing materials (materials with the potential to partially repair damage in the structure of the material)

○ Balazs (2007) investigated the modeling of self-healing materials, starting with biological examples which may potentially be expanded to infrastructure where cracks that develop in the pavement layers may self-heal based on the introduction of microcapsules in the cement matrix (Kessler et al, 2003). The scale requirements and the potential benefit to determine whether the development of such cracks is life-threatening or whether this may be more of a nice-to-have than essentiality is still required.

- The self-healing of fly-ash in the pavement materials has been observed before (Barstis and Crawley, 2000) and can be seen as a nano-scale effect that is utilized already.

- Concrete enhancements 
○ Sobolev and Gutiérrez (2005) described a range of possible effects of nanotechnology developments on concrete in general. The understanding of the bottoms-up manufacturing process that occurs naturally in nature is seen as potentially powerful, as it provides opportunity to possibly obtain cost-effective nanomaterials for use in concretes. CNTs are typically viewed as one of the most promising developments impacting on concrete performance, while the exploitation of the changing properties (i.e. electrical, magnetic and reactivity) of materials at nanoscale also provide novel potential applications in concrete. The requirement for sustainability and cost- and energy-efficiency is again emphasized.

- The incorporation of $\mathrm{TiO}_{2}$ in concrete to render the concrete a material that can perform certain photocatalytic activities has been well developed and applied (Cassar, 2005). Typically, the photocatalytic reaction is applied for the provision of self-cleaning surfaces and also the removal of $\mathrm{NO}_{\mathrm{x}}, \mathrm{SO}_{\mathrm{x}}, \mathrm{NH}_{3}$ and $\mathrm{CO}$ pollution from urban areas through a chemical reaction triggered by naturally occurring ultraviolet light. International pilot projects have already proven the benefits of this development (PICADA, 2006; CAMDEN, 2007).

- Carbon Nanotubes (CNTs)

- Fiber Reinforced Concrete (FRC) is produced when fibers (typically steel or polypropylene fibers) are added to a concrete mix to control plastic shrinkage cracking and drying shrinkage cracking. The fibers also lower the permeability of the FRC and produce greater impact, abrasion and shatter resistance in the FRC. The vital typical properties required for the fibers in FRC include diameter, specific gravity, Young's modulus and tensile strength (Brown et al, 2002). Various researchers have investigated the option of using CNTs as fibers in fiber reinforced concrete.

- Makar et al (2005) showed that the addition of CNTs to a concrete increase the hydration rates and that strong bonds develop between the CNT and the cement paste, while Yakovlev et al (2006) measured increases of up to 70 per cent in the compressive strength of CNT reinforced concrete and decreases of up to 12 per cent in the heat conductivity of the concrete.

- Robertson (2004) stated that the potential benefits of CNT reinforced materials have been rather disappointing as the moduli measured for CNT reinforced materials are typically much 
lower than would be expected based on theoretical calculations. Possible reasons for this may include dispersion problems through the host matrix and the small surface area available for bonding between individual CNTs and the matrix.

$\circ$ One of the potential benefits of CNT reinforcement of concrete that was not found in literature is the fact that CNTs will not corrode in corrosive environments as happens in steel FRC. This benefit may specifically be evaluated for application in marine environments

- Bituminous materials

- The RILEM Technical Committee for Nanotechnology-based Bituminous Materials (NBM) focuses on the identification of material characterization and modeling issues and challenges at the nano- and microstructural level (Rilem, 2009). Issues around temperature and humidity control during sample preparation and characterization also receives attention to ensure that measurements and observations are not affected by adverse material reactions. The expected outcome of this effort is improved bituminous materials with superior environmental and traffic loading resistance.

One of the potential benefits of CNT reinforcement of concrete that was not found in literature is the fact that CNTs will not corrode in corrosive environments as happens in steel FRC. This benefit may specifically be evaluated for application in marine environments

Examples of the potential application of nanotechnology techniques to enhance material properties that are currently under investigation are as follows:

- Thin films or Self Assembled Monolayers (SAM)

- Thin films of nano-sized material can be deposited on the surface of a host material through various techniques. This includes Self Assembled Monolayer (SAM) and sol-gel methods. The objective of such a treatment is to change the properties of the surface of the host material. Typical reasons requiring such a change include incompatibility between the aggregate (host material) and the binder used (e.g. cement or bitumen) and the need to 
improve the bonds between the host and the binder. In some cases the need may also exist to prevent bonding between two materials, and in such cases changes in the surface morphology / chemistry of the two materials may be required.

- In pavement engineering the adhesion between aggregate and bitumen receives ongoing research attention. A relatively good understanding exist regarding the fundamental forces acting on these materials, and it is known that different levels of adhesion exist between different types of aggregate and bitumens (Hefer et al, 2005). In reality, stripping of bitumen from aggregate occurs under certain environmental and loading conditions. The potential of applying SAMs onto aggregates to prevent stripping between the two materials and thereby improving the performance of the asphalt should be evaluated.

- Sanfilippo and Munoz (2009) evaluated the effect of such surfacing layers on concrete processing with enhanced mechanical properties and prevention of deleterious reactions between aggregate and binder some of the main outcomes.

- Some siliceous aggregates react with the alkali hydroxides in cement, causing expansion and cracking over a period of many years (Addis, 2001). This reaction has two forms - alkalisilica reaction (ASR) and alkali-carbonate reaction (ACR). In ASR, aggregates containing certain forms of silica (amorphous micro-crystalline) react with alkali hydroxide in cement to form a gel that swells as it adsorbs water from the surrounding cement paste or the environment. These gels can swell and induce expansive pressures large enough to damage concrete. Pre-coating of these aggregates can prevent the type of reaction, rendering currently unsuitable aggregate economically suitable for concrete applications.

- Nanophosphor

- A major road safety need in rural Africa is the illumination of road pavements to improve visibility and road safety. The potential use of nanophosphors combined with road surfacing materials or paints for this purpose was evaluated at CSIR (Steyn et al, 2005; Steyn, 2008b). Nano-phosphors are nano-scale crystalline structures with a size dependent bandgap that can be altered to change the color of light (Kelsall et al, 2004). If the road can act as the source of the light (be made luminescent) it can play a role in improving road safety as the source of the 
light will not be dependent on external power and the use of a motorized vehicle any more. Current research outputs have shown that nano-phosphors can be added to traditional pavement materials such as concrete, bitumen and road paint to enable these materials to become luminescent after exposure to light, while research is ongoing to further investigate issues such as the increase in luminescence duration, the type of bonds that form between the nano-phosphors and the substrate materials and the up-scaling of manufacturing techniques to enable practical amounts of nano-phosphor to be manufactured.

\section{- Sensors}

- One of the well-publicized possibilities of nanomaterials is the development of sensors that act as part of the substrate that is being observed, thereby allowing very fine measurements on a small scale and obviating the need to add external sensors to a system (Goddard et al, 2007). While external sensors tend to interfere with the mechanics of the system being monitored, the incorporation of sensors as part of the matrix of the system provides the potential that the matrix actually provides feedback and issues around bonding between sensors and the matrix are canceled. The application of CNTs in traffic monitoring (Shi and Chung, 1999) is an example of such application. In this type of applications the transfer of data from the sensor to a data acquisition device and the analysis of data still require further work, especially if the sensors are being distributed inside a pavement of several kilometers length.

- Development of alternative materials

- Bitumen is a by-product of the production of fuel from crude oil. In typical asphalt pavements the bitumen comprises in the region of 0.5 per cent of the mass and between 5 and 17 per cent of the cost of the road. However, if the bitumen is not available an alternative binder is required for the bonding of the aggregates in asphalt. Internationally, the reserves of crude oil are viewed as being decreasing with a range of indications of potential reserves. The direct implication for pavement engineering is that the price of bitumen may increase drastically in future (as is already experienced) as the availability decreases.

- There are various international efforts at development of alternative and sustainable binders (Paige-Green and Steyn, 2005). In this regard the application of manufacturing techniques 
developed in the nanotechnology field, as well as the characterization techniques may assist in the development of new sustainable alternatives that can provide the required properties to ensure that cost-effective construction and maintenance of pavements.

\section{- Other materials}

$\circ$ One of the changes that a material undergoes when used at the nanoscale is that the surface area to volume ratio typically increase drastically. One of the materials often encountered in pavement engineering is naturally occurring clays. These clays pose very specific problems to the pavement engineering field as their response to changes in moisture content and the platelet structure of the material cause most clays to have low friction angles and some to be expansive. Various traditional treatments of the problem include the stabilization of the clay using materials such as lime, treatment with sulphonated petroleum products that affects the ion surface properties (exchangeable ions) of the material or the removal of the material from the pavement structural layers.

- However, research into the behavior of clay minerals in the nanotechnology field (LarsenBasse and Chong, 2005) is providing new insights into the fundamental properties of clays. Application of this new knowledge may lead to alternative methods for the stabilization of the clays found in road reserves, and may thus lead to less expensive methods for using these materials in the pavement structure. This is also an area where the characterization of materials using high resolution equipment such as the SEM and AFM has led to potential new insights into the sub-microscopic properties of the materials, identifying potentially better methods for the treatment of these materials.

\section{Characterization of existing and novel materials}

The developments around characterization techniques that have occurred during the past decade in nanotechnology have opened the door to observations of pavement engineering materials on a scale not available before. As for other fields of study, this brought about a major change in the way that materials are being observed and also the understanding of the behavior of these materials. Some examples of such benefits include the following: 
- Observational techniques

- Observational techniques are used to observe phenomena in engineering and to support the explanation of such phenomena. For pavement engineering this ranges from the macro scale where satellite images are used to observe macro scale phenomena (mainly in terms of geographical, geological and developmental issues) down to the nanoscale where matter is studied in its smallest observable form. Steyn (2007) has shown the hierarchy of possible observations (Table 2) including the smaller scales obtained from the Scanning Electron Microscopy (SEM) and Atomic Force Microscopy (AFM) techniques. These are starting to yield useful results in the understanding of the behavior of engineering materials (Mgangira, 2007a).

Table 2: $\quad$ Hierarchy of possible pavement engineering observational techniques.

- Characterization of materials - AFM

○ Pauli et al (2001) used AFM in characterizing bituminous binders and their respective properties. They correlated the surface morphology with the constituents in the bitumen and concluded that the AFM data may be used to improve the understanding of the precipitation of the asphaltenes in the bitumen and that this information may lead to an improved understanding of the interaction between the surface of the aggregate and the bitumen in asphalt.

- The AFM was used to investigate the structural morphology of crumb rubber bitumen at the interfacial regions, especially during aging (Huang et al, 2006). Masson et al (2006) used phase-detection AFM to evaluate bitumen morphology and found that bitumen can be classified into three groups, based on the different domains or phases visible.

- Work at CSIR is focusing on the correlation between the aging of bituminous binders on the road (a property that severely affects the deterioration of the pavement surface) and the elastic stiffness of the binders as measured using the AFM. Initial data focused on the surface 
morphology and a clear difference could be observed between the surface morphology of a bituminous binder that was aged at different temperatures. In Figure 2 the overall difference in the surface morphology for four binder types aged at three temperatures can be observed. Research in this area is continuing, with the focus on improving the understanding and potential correlation between surface morphology and performance of bitumen.

\section{Figure 2: Surface morphologies of four bituminous binders as aged at three different temperatures and observed using the AFM.}

- Characterization of materials - SEM

- Mgangira (2007b) used the SEM to evaluate the microtexture of two similar sands that behaved differently when being stabilized using various non-standard soil stabilizers. None of the typical engineering tests provided insight into the reason why the stabilization did not work similarly for the two types of sands evaluated. The SEM investigation showed the difference in terms of fines that were not identified in the standard grading analysis of the sands, which allowed the stabilizers to bond better with the sand grains. In Figure 3 SEM images of the two types of sands are shown, with the fines visible on the right image.

Figure 3: $\quad$ SEM images of two sands showing traces of small fractions (right) (Mgangira, 2007b).

\section{CHALLENGES}

Although a large number of potential ideas and applications for nanotechnology and pavement engineering exist, it is also important to remain realistic and identify and accept the current limitations and challenges inherent in this field. In this section a short summary of those challenges and limitations potentially affecting these applications are provided. 


\section{Costs}

The costs of most nanotechnology equipment and materials are currently relatively high. This is partly due to the novelty of the technology, but also due to the complexity of the equipment. However, in the case of the nano materials, costs have been shown to decrease over time and the expectations are that, as manufacturing technologies improve, the costs of the materials will decrease. Whether such decreases will render the materials as run-of-the-mill pavement engineering materials will have to be seen. Current opinion is that in special cases, the materials will enable unique solutions to complicated problems that cause them to be cost effective, which will lead to large scale application of these specific technologies. In other cases the traditional methods for treating the problem may still remain the most cost effective. As indicated earlier, the job of the engineer is to solve real-world problems and provide a facility to the general public at a reasonable cost.

\section{Environment}

The effect of various nanomaterials on the natural environment is a hot topic in nanotechnology and environmental research. Uncertainty regarding the potential effects of materials that exist on the nanoscale with properties that are different than when using the material on a micro or macro scale has led to various investigations (NNI, 2003). Some work in this regard shows that the potential effects may be minimal (Tong et al, 2007). As pavements are constructed in the natural environment, all materials (including nanomaterials) used in the construction and maintenance of pavements need to be compatible to the natural environment and their effects on the natural environment should be minimal. Typical potential problems in this regard include the leaching of materials into groundwater, release of materials into airways through the generation of dust on unpaved roads and the exposure to potentially harmful materials during construction and maintenance operations.

However, the reasons for using nanomaterials often include specifically the different performance of the material on the nanoscale, and also the different effect that it has on the environment when used on the nanoscale. In cases such as improved methods for purification of water, the different effect on potentially deadly microbes in the water is specifically the reason why the nanomaterials are being 
used (Hassan, 2005; Savage and Diallo, 2005). The application of nanomaterials in the fight against deadly diseases such as tuberculosis (TB), malaria and HIV (Maclurcan, 2005) should also not be misjudged, as the focus of the application is specifically to have an effect on natural organisms. A clear distinction is thus required between controlled and sought-after effects on the environment and uncontrolled and unexpected effects on the environment.

\section{Scale}

The unique environment of the pavement engineer who works with large volumes of material should always be appreciated when evaluating potential applications of nanotechnology. The effects on manufacturing capacity and performance of the nanomaterials when combined with bulk aggregates and binders should be evaluated to ensure that the beneficial (nanoscale) properties are still applicable and cost- and energy-efficient at these scales. This challenge has been addressed earlier in the paper.

\section{CONCLUSIONS}

Based on the information and discussions in this paper, the following conclusions are drawn:

- The application of nanotechnology developments in the field of pavement engineering can potentially lead to advances in solving general engineering problems;

- Most of these applications, however, first need to be scaled to the dimensional applications that are typical for the pavement engineering environment;

- The technical- and cost-effectiveness of available technologies should both be evaluated as part of the evaluation of nanotechnology solutions in engineering;

- Fundamental research into the properties of engineering materials to improve the understanding regarding their performance is an important output of nanotechnology characterization of pavement materials, and 
- The development of novel materials and the improvement of existing materials in response to scarcity of natural materials become a possibility through application of nanotechnology techniques on traditional pavement materials.

\section{RECOMMENDATIONS}

Based on the information and discussions in this paper, the following recommendations are made:

- The gap between scientists (specifically physicists and chemists) and engineers should be narrowed to enable the potential of nanotechnology innovations to be applied in appropriate areas of engineering to support the general public good;

- Scientists should continue with their focus on basic and oriented basic research, providing the required building blocks for engineers to construct a better environment;

- Engineers should actively and regularly evaluate the available technologies (specifically in the field of nanotechnology, as it evolves rapidly) to identify potential solutions to problems that they are required to address in society, and

- Challenges such as the potential impact of nanomaterials on the natural environment around pavements should receive the required attention to ensure that solutions to pavement engineering questions do not cause new hazards to the public utilizing the natural and built environment.

\section{ACKNOWLEDGEMENTS}

The author would like to acknowledge the generous support of CSIR Built Environment and the University of Pretoria in the work conducted in the area of nanotechnology for engineering on which this paper was based. 


\section{REFERENCES}

Addis, B.J. (2001). “Fulton’s Concrete Technology.” Portland Cement Institute, Midrand, South Africa.

Balazs, A.C. (2007). “Modeling self-healing materials.” Materialstoday, Vol. 10, Nr. 9, 18-23

Barstis, W.F. and Crawley, A.B. (2000). “The use of fly-ash in highway construction.” Report 84DP59-MS-05, Mississippi Department of Transportation, Jackson, MS.

Brown, R., Shukla, A. and Natarajan, K.R. (2002). "Fiber reinforcement of concrete structures." URITC Project 536101, University of Rhode Island Transportation Center, Kingston, RI, USA.

Buehler, M.J. and Ackbarow, T. (2007). "Fracture mechanics of protein materials.” Materialstoday, Vol. 10, Nr. 9, 46-58.

CAMDEN. (2007). "Pioneering paving to tackle air pollution.” <www.camden.gov.uk>. (Accessed March 2007).

Cassar, L. (2005). "Nanotechnology and photocatalysis in cementitious materials.” Proc., 2nd Int. Symp. on Nanotechnology in Construction. NANOC (Centre for Nanomaterials Applications in Construction), Bilbao, Spain, Nov 13-16, 277-283.

Goddard III, W.A., Brenner, D.W., Lyshevski, S.E. and Iafrate, G.J. (2007). "Handbook of nanoscience, engineering, and technology, 2nd edition.” CRC Press, Boca Raton, Florida.

Hassan, M.H.A. (2005). "Small things and big changes in the developing world.” Science, Vol. 309. No. 5731. 65-66. DOI: 10.1126/science.1111138.

Hefer, A., Little, D.N. and Lytton, R.L. (2005). “A synthesis of theories and mechanisms of bitumenaggregate adhesion including recent advances in quantifying the effects of water.” J. Assoc. Asphalt Paving Technologists, March 7-9, Long Beach, California, USA.

Huang, S-C. Pauli, A.T., Beemer, A. and Robertson, R.E. (2006). "Influence of crumb rubber on the fatigue performance of asphalt pavement.” Proc., 10th Int. Conf. on Asphalt Pavements, ICAP, Quebec City, Canada, Aug 12-17.

Kelsall, R.W. Hamley, I.W., and Geoghegan, M. (2004). "Nanoscale science and technology.” John Wiley and Sons, Ltd, Chisester, England. 
Kessler, M.R., Sottos, N.R. and White, S.R. (2003). "Self-healing structural composite materials." Composites: Part A 34, 743-753.

Kumar, S. and Curtin, W.A. (2007). “Crack interaction with microstructure.” Materialstoday, Vol. 10, Nr. 9, 34-44.

Larsen-Basse, J. and Chong, K.P. (2005). "Nanomaterials in construction and rehabilitation: Contributions and perspectives of the US National Science Foundation.” Proc., 2nd Int. Symp. on Nanotechnology in Construction, NANOC (Centre for Nanomaterials Applications in Construction), Bilbao, Spain, Nov 13-16, 17-19.

Maclurcan, D.C. (2005). “Nanotechnology and developing countries. Part 1: What possibilities.” J. Nanotechnology Online. DOI: 10.2240/azojono0104.

Maher, M., Uzarowski, L., Moore, G. and Aurilio, V. (2006). "Sustainable pavements - Making the case for longer design lives for flexible pavements.” Proc., 51st Annual Conf. of the Canadian Technical Asphalt Association, CTAA, Charlottetown, Prince Edward Island, Canada, 44-56.

Makar, J., Margeson, J. and Luh, J. (2005). “Carbon nanotube/cement composites - early results and potential applications.” Proc. 3rd Int. Conf. on Construction Materials: Performance, Innovations and Structural Implications, University of British Columbia, Vancouver, B.C., Aug 22-24, 1-10.

Masson, J-F., Leblond, V. and Margeson, J. (2006). "Bitumen morphologies by phase-detection atomic force microscopy.” J. Microscopy, Vol. 221. Pt 1 January, 17-29.

Meyyapan, M., Iyuke, S.E. and Falcon, R. (2007). “Carbon engineering and nanotechnology course.” Short course presented at the University of the Witwatersrand, Johannesburg, South Africa, April 2-4. Mgangira, M. (2007a). "Use of scanning electron microscope in road materials characterization.” CSIR BE report CSIR/BE/IE/IR/2007/024/B, Pretoria, South Africa.

Mgangira, M. (2007b). "Particle bonding characterization of a sand mixture treated with nontraditional additives.” Proc. 86th Transportation Research Board (TRB) meeting, TRB, Washington D.C.

NNI, (2003). “Nanotechnology and the environment.” Report of a National Nanotechnology Initiative Workshop, May 8-9, Arlington, VA. 
OECD. (2002). “Frascati Manual 2002.” Organisation for Economic Co-operation and Development (OECD), ISBN 92-64-19903-9, Paris, France.

Paige-Green, P. and Steyn, W.J.vdM. (2005). “An investigation into the need for bitumen alternatives for road infrastructure.” CSIR BE Report TR-2005/09. CSIR Built Environment, Pretoria, South Africa.

Pauli, A.T., Branthaver, J.F., Robertson, R.E. and Grimes, W. (2001). “Atomic Force Microscopy investigation of SHRP asphalts.” Proc. Symp. on Heavy Oils and Residue Compatibility and Stability, 221st National Meeting, American Chemical Society: Division of Petroleum Chemistry, San Diego, Ca, April 1-5.

PIARC Home Page. <www.piarc.org/en/technical-committees> (accessed September 2007).

PICADA, (2006). “Official presentation, Innovative facade coatings with de-soiling and de-polluting properties.” EC GRD1-2001-40449, GTM Construction, Nanterre Cedex, France.

RILEM, (2009). “Technical Committee NBM (Nanotechnology-based Bituminous Materials) General Information Web Page. www.rilem.net/tcDetails.php?tc=NBM (accessed April 2009).

Robertson, J. (2004). “Realistic applications of CNTs.” Materialstoday, Vol. 7, Nr. 10, 46-52.

Sanfilippo, J.M. and Munoz, J. (2009). “Using nanotechnology to play with aggregate mineralogy: Application in concrete processing." Presentation at the Nanotechnology-based Concrete Materials Task Force Meeting (AFN15T), Transportation Research Board Meeting, January 14, 2009.

Savage, N. and Diallo, M.S. (2005). "Nanomaterials and water purification: Opportunities and Challenges.” J. Nanoparticle Research. Volume 7, Numbers 4-5, October, Springer Netherlands.

Shi, Z-Q. and Chung, D.D.L. (1999). "Carbon fiber-reinforced concrete for traffic monitoring and weighing in motion.” Cem Concr Res 29, 435-439.

Sobolev, K. and Gutiérrez, M.F. (2005). "How nanotechnology can change the concrete world.” American Ceramic Society Bulletin, Vol. 84, No. 10.

Steyn, W.J.vdM. (2007). “Applications of observational techniques in engineering.” Proc., 26 $6^{\text {th }}$ Annual Transportation Conference, SATC, Pretoria, South Africa. 
Steyn, W.J.vdM., Hillie, T., Swart, H. and Revaprasadu, N. (2007). "Nano-particle and -phosphors in infrastructure.” PG report PP/TH 2006/049 - CSIR/BE/IE/IR/2007/020/B. CSIR Built Environment, Pretoria, South Africa.

Steyn, W.J.vdM. (2008a). "Research and application of nanotechnology in transportation.” Proc., 25 Annual Transportation Conference, SATC, Pretoria, South Africa.

Steyn, W.J.vdM. (2008b). “Development of autoluminescent surfacings for concrete pavements.” J. Transportation Research Board, 2070, 22-31.

Sunter, C. (1996). “The high road: Where are we now.” Tafelberg Publishers, Cape Town, South Africa, ISBN 0624035271.

Tong, Z., Bischoff, M. and Nies, L. (2007). "Impact of Fullerene (C60) on a soil microbial community.” B. Environ. Sci. Technol. 2007, 41, 2985-2991.

Yakovlev, G., Kerienè, J., Gailius, A. and Girniene, I. (2006). "Cement based foam concrete reinforced by carbon nanotubes.” Materials Science (Medžiagotyra), Vol. 12, No. 2. 


\section{FIGURE CAPTIONS}

Figure 1: $\quad$ The path of innovation (adapted from Sunter, 1996).

Figure 2: $\quad$ Surface morphologies of four bituminous binders as aged at three different temperatures and observed using the AFM.

Figure 3: $\quad$ SEM images of two sands showing traces of small fractions (right) (Mgangira, 2007b). 


\section{TABLES}

Table 1: $\quad$ PIARC Technical Committees for road infrastructure (PIARC, 2007).

\begin{tabular}{|l|l|l|}
\hline Technical Committee Name & Identified Issues & Summarized strategies \\
\hline \multirow{2}{*}{ Road pavements } & $\begin{array}{l}\text { Selecting adequate pavement } \\
\text { types and road techniques }\end{array}$ & $\begin{array}{l}\text { Develop long life / perpetual } \\
\text { pavements }\end{array}$ \\
\cline { 2 - 3 } & Maintaining pavements & $\begin{array}{l}\text { Recycling of materials in } \\
\text { existing pavements }\end{array}$ \\
\hline $\begin{array}{l}\text { Road bridges and related } \\
\text { structures }\end{array}$ & $\begin{array}{l}\text { Increasing durability and safety } \\
\text { of structures }\end{array}$ & $\begin{array}{l}\text { Focus on methods to postpone } \\
\text { maintenance and prolong life }\end{array}$ \\
\hline $\begin{array}{l}\text { Earthworks, drainage and } \\
\text { subgrade }\end{array}$ & $\begin{array}{l}\text { Promoting optimal use of local } \\
\text { materials }\end{array}$ & $\begin{array}{l}\text { Identify methods for treating } \\
\text { soils and application of local / } \\
\text { in situ materials }\end{array}$ \\
\hline $\begin{array}{l}\text { Management of road } \\
\text { infrastructure assets }\end{array}$ & Not applicable to this paper & \\
\hline Road / Vehicle interaction & \multicolumn{2}{|l}{} \\
\hline
\end{tabular}


Table 2: $\quad$ Hierarchy of possible pavement engineering observational techniques.

\begin{tabular}{|c|c|c|c|}
\hline $\begin{array}{c}\text { General wavelength } \\
\text { bands }\end{array}$ & $\begin{array}{l}\text { X-ray wavelength } \\
10 \text { to } 10-2 \text { nm }\end{array}$ & $\begin{array}{l}\text { Visible wavelength } \\
400 \text { to } 700 \mathrm{~nm}\end{array}$ & $\begin{array}{l}\text { Infrared wavelength } \\
103 \text { to } 106 \mathrm{~nm}\end{array}$ \\
\hline \multirow{6}{*}{$\begin{array}{l}\text { Indication of currently } \\
\text { used technology and } \\
\text { resolution of features }\end{array}$} & & $\begin{array}{l}\text { Satellite images } \\
\text { Mm resolution }\end{array}$ & $\begin{array}{l}\text { Infrared satellite } \\
\text { images } \\
\text { Mm resolution }\end{array}$ \\
\hline & NCI & $\begin{array}{l}\text { Aerial photographs / } \\
\text { LIDAR } \\
\text { km resolution }\end{array}$ & $\begin{array}{l}\text { Infrared airborne } \\
\text { images } \\
\text { km resolution }\end{array}$ \\
\hline & & $\begin{array}{l}\text { Standard photos } \\
\text { m resolution }\end{array}$ & \multirow{4}{*}{ NCR } \\
\hline & $\begin{array}{l}\text { Computerized } \\
\text { Tomography (CT) } \\
\text { scans } \\
\text { Mm resolution }\end{array}$ & $\begin{array}{l}\text { Microscope images } \\
\text { mm resolution }\end{array}$ & \\
\hline & $\begin{array}{l}\text { SEM images } \\
\text { Mm resolution }\end{array}$ & NCR & \\
\hline & NCR & $\begin{array}{l}\text { AFM images } \\
\text { nm resolution }\end{array}$ & \\
\hline
\end{tabular}

NCI - No Current Images used typically in pavement engineering. 